\title{
"CO2 emissions analysis for East European countries: the role of underlying emission trend"
}

Denizhan Guven (D http://orcid.org/0000-0003-1605-7661

AUTHORS

M. Özgür Kayalica (D https://orcid.org/0000-0001-9828-7385

R https://publons.com/researcher/1984150/m-ozgur-kayalica/

Gülgün Kayakutlu (D https://orcid.org/0000-0001-8548-6377

ARTICLE INFO

Denizhan Guven, M. Özgür Kayalica and Gülgün Kayakutlu (2020). CO2 emissions analysis for East European countries: the role of underlying emission trend. Environmental Economics, 11(1), 67-81. doi:10.21511/ee.11(1).2020.07

DOI http://dx.doi.org/10.21511/ee.11(1).2020.07

RELEASED ON Friday, 05 June 2020

RECEIVED ON Monday, 11 May 2020

ACCEPTED ON Thursday, 04 June 2020

\section{(cc) EY}

LICENSE

This work is licensed under a Creative Commons Attribution 4.0 International License

JOURNAL

"Environmental Economics"

ISSN PRINT $1998-6041$

ISSN ONLINE 1998-605X

PUBLISHER LLC "Consulting Publishing Company "Business Perspectives"

FOUNDER LLC "Consulting Publishing Company "Business Perspectives"

NUMBER OF REFERENCES

30

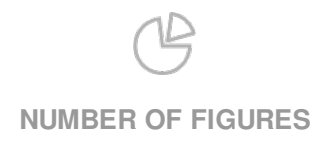

6
NUMBER OF TABLES

1

(C) The author(s) 2021. This publication is an open access article. 


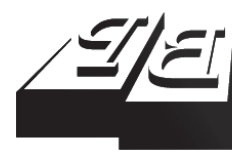

\section{BUSINESS PERSPECTIVES}

LLC "CPC "Business Perspectives" Hryhorii Skovoroda lane, 10, Sumy, 40022, Ukraine www.businessperspectives.org

Received on: $11^{\text {th }}$ of May, 2020 Accepted on: $4^{\text {th }}$ of June, 2020 Published on: $5^{\text {th }}$ of June, 2020

(c) Denizhan Guven, M. Ozgur Kayalica, Gulgun Kayakutlu, 2020

Denizhan Guven, Research Assistant, Eurasia Institute of Earth Sciences, "Technological and Economic Research and Development Center", Istanbul Technical University, Turkey.

M. Ozgur Kayalica, Dr., Professor, Energy Institute, "Technological and Economic Research and Development Center", Istanbul Technical University, Turkey.

Gulgun Kayakutlu, Dr., Professor, Energy Institute, "Technological and Economic Research and Development Center", Istanbul Technical University, Turkey.

\title{
$\mathrm{CO}_{2}$ EMISSIONS ANALYSIS FOR EAST EUROPEAN COUNTRIES: THE ROLE OF UNDERLYING EMISSION TREND
}

\begin{abstract}
This paper aims to analyze the impact of energy consumption, economic structure, and manufacturing output on the $\mathrm{CO}_{2}$ emissions of East European countries by applying the Structural Time Series Model (STSM). Several explanatory factors are used to construct the model using annual data of the 1990-2017 period. The factors are: total primary energy supply, GDP per capita and manufacturing value added, and, finally, a stochastic Underlying Emission Trend (UET). The significant effects of all variables on $\mathrm{CO}_{2}$ emissions are detected. Based on the estimated functions, $\mathrm{CO}_{2}$ emissions of Belarus, Ukraine, Romania, Russia, Serbia, and Hungary will decrease, by 2027, to 53.2 Mt, 103.2 Mt, 36.1 Mt, 1528.2 Mt, 36 Mt, and 36.1 Mt, respectively. Distinct from other countries, $\mathrm{CO}_{2}$ emissions of Poland will extend to $312.2 \mathrm{Mt}$ in 2027 due to the very high share of fossil-based supply (i.e., coal and oil) in Poland. The results also indicate that the most forceful factor in $\mathrm{CO}_{2}$ emissions is the total primary energy supply. Furthermore, for Poland, Romania, Hungary, and Belarus, the long-term impact of economic growth on $\mathrm{CO}_{2}$ emissions is negative, while it is positive for Russia, Ukraine, and Serbia. The highest long-term manufacturing value-added elasticity of $\mathrm{CO}_{2}$ emissions is calculated for Serbia and Belarus.
\end{abstract}

Keywords

JEL Classification

\section{INTRODUCTION}

Following the first industrial revolution, global $\mathrm{CO}_{2}$ emissions have been ascending expeditiously. $\mathrm{CO}_{2}$ concentration was almost constant and ranged between approximately 270-285 ppm (Ritchie \& Roser, 2019). For the first time in the history of humanity, global daily $\mathrm{CO}_{2}$ concentration has been recorded as 417.91 ppm in April 2020 (Scripps Institution of Oceanography, 2020). Despite the continuous efforts of the United Nations and improving commitments, $\mathrm{CO}_{2}$ kept increasing and hit this peak. Therefore, it is important to boost more research on the subject.

Notwithstanding, each country's contribution to the global $\mathrm{CO}_{2}$ emissions is not equal, and it has been changing over time. Compared to many other regions, Eastern Europe shows a considerably reasonable emission level. That is why the region and its $\mathrm{CO}_{2}$ account is pretty much neglected. This paper attempts to fill in this research gap in terms of considering the economic structures, energy demands, manufacturing values, and underlying $\mathrm{CO}_{2}$ emissions trends of these countries. As seen from Figure 1, the share of East European countries, including Russia, Belarus, Ukraine, Hungary, Poland, Serbia, and Romania, has been continuously decreasing since the 1990s. Apart from Russia, 
the rest of the countries in the region show even a lower pattern. The East European countries, except Russia, Belarus, Ukraine, Hungary, Poland, Serbia, and Romania, are omitted due to data being static during the estimation period. The data of two more countries, China and India, were included as a benchmark to make the comparison more interesting. The share of China and India have been persistently increasing. Therefore, they are also included in Figure 1 to show the difference in the contribution of each country to the global $\mathrm{CO}_{2}$ emissions better.

In parallel with the Intergovernmental Panel on Climate Change (IPCC), 195 countries put signatures to the first adstrictory climate change treaty at the Paris Climate Conference (COP21). Signatory states' governments agreed to confine the increase in GMST below $2^{\circ} \mathrm{C}$ in comparison to the pre-industrial levels, and they have targeted decreasing their $\mathrm{CO}_{2}$ emissions until 2030. As declared in Intended Nationally Determined Contribution (INDC), based on taking 1990 as the base year for calculation, the targeted greenhouse gas (GHG) reduction rates of Ukraine, Poland, Hungary, and Romania are 40\%, while that of Belarus, Russia and Serbia are 28\%, 25-30\%, and 9.8\%, respectively (UNFCCC, 2015).

Within this context, the quantitative analysis of $\mathrm{CO}_{2}$ emissions plays a critical role in the determination of energy and environmental policies. Besides, it is essential to achieve $\mathrm{CO}_{2}$ mitigation targets for 2030. Thus, determining key drivers of $\mathrm{CO}_{2}$ emissions for each selected country is crucial to decide regulations and policies applied to achieve their mitigation targets.

In addition to the most common key drivers of $\mathrm{CO}_{2}$ emissions, the impact of underlying $\mathrm{CO}_{2}$ emissions trend, such as developments in technology, changes in human behaviors, and legislations/regulations, etc. is not adequately investigated for $\mathrm{CO}_{2}$ emission forecasts. In this study, this gap in the $\mathrm{CO}_{2}$ emission forecasting area is fulfilled by adding a stochastic variable, so-called Underlying Emission Trend (UET), into the time series analysis. The notation of the Underlying Energy Demand Trend (UEDT) has been using only for energy demand forecasting studies. In this study, this concept is adapted to forecast $\mathrm{CO}_{2}$ emissions for the first time.

The literature background of $\mathrm{CO}_{2}$ emissions decomposition studies, mainly focused on East European countries, is summarized in the next section. In section 2, the methodology and the data for the analysis are presented. The proposed model and estimation results are given in section 3 . The forecasting assumptions and results are also shown in the same section. In section 4, all estimation results are discussed and compared with previous studies. Finally, the last section concludes with an emphasis on possible policies and regulations.

\section{LITERATURE REVIEW}

The anthropogenic greenhouse gases (GHG) emissions can be ranked starting with the lead of $\mathrm{CO}_{2}$, which has more than $73 \%$ share in anthropogenic GHG emissions that takes an essential place among greenhouse gases. It is followed by methane $\left(\mathrm{CH}_{4}\right)$ and nitrous oxide $\left(\mathrm{N}_{2} \mathrm{O}\right)$, with shares of $18 \%$ and $6 \%$, respectively (Olivier, Schure, \& Peters, 2018). GHGs engender more thermal radiation absorption than usual. For this reason, GHGs are stated as the most significant cause of global warming by scientists. Further, the reports published by the Intergovernmental Panel on Climate Change (IPCC) declared that the global mean surface temperature (GMST) from 2006 to 2015 was roughly $0.87^{\circ} \mathrm{C}$ greater than the period between mid- $18^{\text {th }}$ and the beginning of $20^{\text {th }}$ century, named as pre-industrial era (Stocker, Qin, Plattner, Tignor, Allen, ... \& Midgley, 2013).

An increase in global $\mathrm{CO}_{2}$ emissions is mostly caused by the consumption of primary energy sources such as coal and oil. The changes in combustion-based $\mathrm{CO}_{2}$ emissions in terms of fuel between 1978 and 2017 are shown in Figure 2. Based on data from the International Energy Agency, during the period between 1978 and 2017, the $\mathrm{CO}_{2}$ emissions caused by the combustion of coal, oil, and gas increased 133\%, $32 \%$, and $169 \%$, respectively (IEA, 2019). 

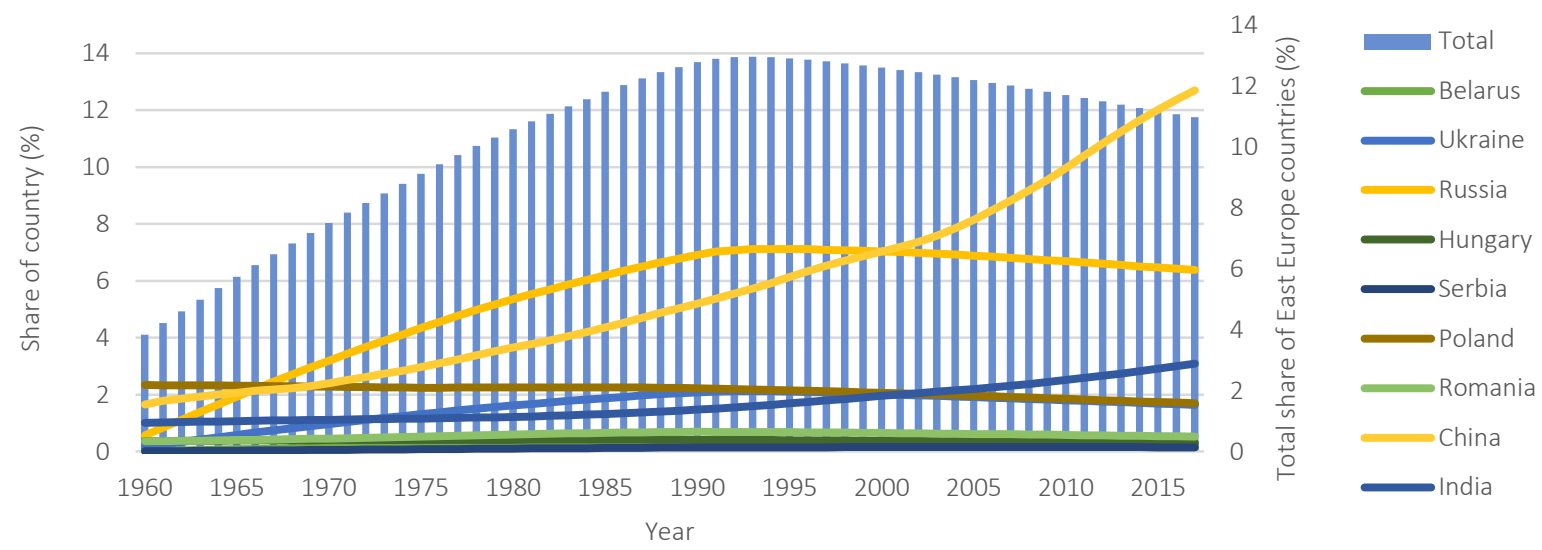

Figure 1. Global $\mathrm{CO}_{2}$ emissions shares of East European countries, China, and India

The literature on GHGs analysis that depends on energy supply and economic structure from different countries is stunning. Nonetheless, there are very few studies in the literature that are specific to the East European area. This section endeavors to review the literature that constitutes the backbone of this study.

In this regard, using the Artificial Neural Network (ANN) method, Antanasijević, Ristić, Perić-Grujić, and Pocajt (2014) develop a model to forecast $\mathrm{CO}_{2}$ emissions of 28 European countries comprising Hungary, Poland, and Romania. Sustainability, economic characteristics, and industrial indicators of the period 2004-2010 are analyzed as model inputs. The outcome of this analysis shows that gross domestic energy consumption is the most important factor that affects GHG emissions, whereas GDP and "GDP in the industry" have the least impact. In a similar study, Jebli, Farhani, and Guesmi (2020) investigate the impact of the economic structure, renewable energy consumption, industrial, and service value-added on the $\mathrm{CO}_{2}$ emissions for 102 countries, including Ukraine, Belarus, and Russia, that are classified by four income levels. The results of the Generalized Method of Moments and Granger causality test revealed that, regarding the lower-middle-income countries such as Ukraine and upper-middle-income countries such as Belarus and Russia, the economic growth has a negative impact on the $\mathrm{CO}_{2}$ emissions. In contrast, the impact of industrial value added on the $\mathrm{CO}_{2}$ emissions is positive.

By taking into account the technology heterogeneity, Wei, Yan Li, Wu, and Yingbo Li, (2019) apply the Metafrontier Malmquist Luenberger Index
(MML) decomposition method to specify the priority of signatory states of COP21 to advance their $\mathrm{CO}_{2}$ emission efficiencies. Similar to Jebli, Farhani, and Guesmi (2020), signatory countries of COP21 are divided into four levels of income regarding Word Bank Development Indicators. The results of empirical analyses exhibited that innovation and improvement in energy technology is the key power to advance $\mathrm{CO}_{2}$ emissions efficiency. Likewise, using the Environmental Kuznets Curve (EKC) and the Environmental Logistic Curve (ELC) methods, Perez-Suarez and Lopez-Menendez (2015) analyze the goodness of fit and the forecasting accuracy for 175 countries. The empirical output shows that the sufficiency of both methods is quite significant to explain the $\mathrm{CO}_{2}$ emissions for different countries. Grytten and Koilo (2019) aim to examine the impact of economic development, energy consumption, and trade on $\mathrm{CO}_{2}$ emissions for eleven East European countries. The EKC method usage shows that income elasticity of all eleven countries is positive, and Ukraine's $\mathrm{CO}_{2}$ emissions are the most sensitive to the change in economic growth. Furthermore, total energy consumption has a negative impact on the environment as it enhances the level of $\mathrm{CO}_{2}$ emissions.

Dissimilar to the previous studies, Köne and Büke (2010) aim to forecast the energy-related $\mathrm{CO}_{2}$ emissions using trend analysis approach method for the top 25 countries, including Russia, Ukraine, and Poland, based on $\mathrm{CO}_{2}$ emissions data from 1971 to 2007. Thus, the forecast analysis is run only for eleven countries. The results are also compared with International Energy Outlook 2009 of the U.S. Department of Energy. They show that the projections of this study are in a tolerable range. 


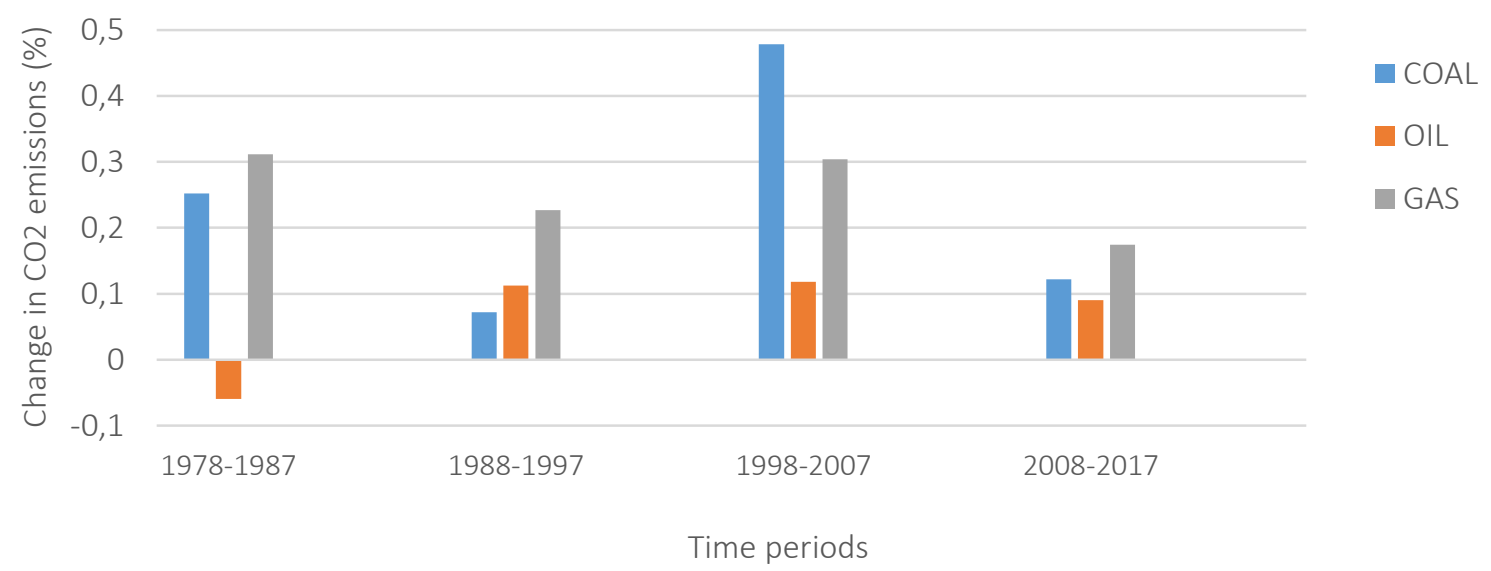

Figure 2. Changes in released $\mathrm{CO}_{2}$ emissions in terms of fuel resource

More recently, Song and Zhang (2019) analyze the movement of $\mathrm{CO}_{2}$ emissions using the gravity theory. To diagnose the key elements of gravity movement, they also implement the contribution decomposition method and study the decoupling state of $\mathrm{CO}_{2}$ emissions for different countries. It is shown that the gravity midpoint of global $\mathrm{CO}_{2}$ emissions shifted to the southeast from 1965 to 2015. Furthermore, in 17 developing countries, including Belarus, Romania, and Poland, economic development is decoupled from $\mathrm{CO}_{2}$ emissions from 2010 to 2015.

Though there are numerous researches focused on the $\mathrm{CO}_{2}$ emissions in the East European countries, the effect of underlying $\mathrm{CO}_{2}$ emissions trend (e.g., changes in human behaviors and legislations/regulations, etc.) is not adequately examined for East European countries. This study undertakes to fill in this gap simply by adding a stochastic variable, so-called Underlying Emission Trend (UET), into the time series analysis.

\section{METHODOLOGY AND DATA}

The methodology and the data used in this research will be presented in this section.

\subsection{Methodology}

The co-integration technique has been widely applied in the forecasting models for a long time (Hendy \& Juselius, 2000). Nonetheless, both the co-integra- tion method and unit-root test have been criticized because of their decrepit statistical features and unnecessary and misleading procedure (Harvey, 1997; Maddala \& Kim, 1998). As an alternative method, Harvey, Henry, Peters, and Wren-Lewis (1986) developed a so-called Structural Time Series Model (STSM) by combining the interpretation of the regression model and the elasticity of time series model.

STSM is a very useful model for the unobservable stochastic trends changing over time. Thus, the mixture of STSM and Autoregressive Distribution Lag (ARDL) may be quite proper to establish forecasting functions. By both stochastic trend and seasonality, it is possible to determine the elasticities of descriptive variables.

In addition to STSM, Hunt, Judge, and Ninomiya (2000) introduce the notion of Underlying Energy Demand Trend (UEDT) as a factor for exogenous effects, including development in technical progress, energy efficiency improvements, changes in human behaviors, economy, and environmental regulations. In this context, in this study, STSM and the notion of UEDT are implemented to form a forecasting model for $\mathrm{CO}_{2}$ emissions of the aforementioned countries for the first time.

Herewith, the aggregate $\mathrm{CO}_{2}$ emissions are identified by the following equation:

$$
C_{t}=f\left(E_{t}, Y_{t}, P_{t}, M_{t}, U E T_{t}\right),
$$

where $E_{t}, Y_{t}, P_{t}, M_{t}, U E T_{t}$ represent the total primary energy supply, GDP per capita, population, 
manufacturing added value, and underlying $\mathrm{CO}_{2}$ emissions trend, respectively. A dynamic ARDL is used to estimate equation (1) as follows:

$c_{t}=\sum_{i=1}^{2} \alpha_{i} c_{t-i}+$

$+\sum_{i=0}^{2}\left[\vartheta_{i} e_{t-i}+\gamma_{i} y_{t-i}+\delta_{i} p_{t-i}+\theta_{i} m_{t-i}\right]+$

$+U E T_{t}+\varepsilon_{t}$

where $c_{t}, e_{t}, v_{t}, p_{t}, m_{t}$ are natural logarithms of $C_{t}$, $E_{t}, Y_{t}, P_{t}$, and $M_{t}$ in a year, respectively. The coefficients $\vartheta_{0}, \gamma_{0}, \delta_{0}$ and $\theta_{0}$ stand for the short-term impact elasticities of primary energy supply, GDP per capita, population, and manufacturing added value, respectively, whereas $\varepsilon$ represents a random white noise error term. Additionally, the longterm primary energy supply, GDP per capita, population, and manufacturing added value may be estimated by

$\Gamma=\frac{\vartheta_{0}+\vartheta_{1}+\vartheta_{2}}{1-\alpha_{1}-\alpha_{2}}, \Delta=\frac{\gamma_{0}+\gamma_{1}+\gamma_{2}}{1-\alpha_{1}-\alpha_{2}}$,

$\Pi=\frac{\delta_{0}+\delta+\delta_{2}}{1-\alpha_{1}-\alpha_{2}}$, and $\Theta=\frac{\theta_{0}+\theta_{1}+\theta_{2}}{1-\alpha_{1}-\alpha_{2}}$,

respectively (Atalla \& Hunt, 2016).

Following Harvey, Henry, Peters, and Wren-Lewis (1986), Underlying Trend (UT) is a stochastic trend presumed by the STSM as:

$$
\begin{aligned}
& \mu_{t}=\mu_{t-1}+\beta_{t-1}+\eta_{t}, \eta_{t} \sim \operatorname{NID}\left(0, \sigma_{\eta}^{2}\right), \\
& \beta_{t}=\beta_{t-1}+\xi_{t}, \xi_{t} \sim \operatorname{NID}\left(0, \sigma_{\xi}^{2}\right) .
\end{aligned}
$$

The notation $\mu_{t}$ and $\beta_{t}$ represent the level and slope of the UET, respectively. Moreover, the parameters $\eta_{t}$ and $\xi_{t}$ are the mutually uncorrelated white noise disturbances having zero means and variances $\sigma^{2}$ and $\sigma_{\xi}^{2}$. These variances also are called hyper-parameters. The parameters $\eta_{t}$ and $\xi_{t}$ designate the shape of the stochastic trend factor (Harvey \& Shephard, 1993).

It is also very crucial to include irregular (Irr), slope (Slp), and/or level (Lvl) interventions into the established model to assure that the auxiliary residuals have a normal distribution. These interventions might present some information about extraordinary structural breaks and variations in the estimation period (Harvey \& Koopman, 1992). In light of such information, Dilaver and Hunt (2011) present the UET as:

$U E T_{t}=\mu_{t}+$ irregular interventions +

+ level interventions + slope interventions.

Equitation (2) is determined by the combination of Kalman filter and maximum likelihood. The software package program STAMP 8.3 is used to run the established model (Koopman, Harvey, Doornik, \& Shephard, 2007).

\subsection{Data}

In this study, data were gathered from various sources. The yearly $\mathrm{CO}_{2}$ emissions $(\mathrm{Mt})$ and the total primary energy supply (Mt) data from 1990 to 2017 were taken from the International Energy Agency (IEA, 2019). Furthermore, annual GDP per capita and manufacturing value added of certain countries were collected from the World Bank (World Bank, 2019a, 2019b). The change in TPES and emissions during the estimation period are shown in Figure 3. The sizes of the circles are in direct proportion to the GPD per capita of each country.

\section{ESTIMATION RESULTS AND FORECAST RESULTS}

\subsection{Estimation results}

In the estimation period, four different model specifications, namely stochastic levels/stochastic slope, stochastic level/fixed slope, stochastic level/ no slope, and fixed level/fixed slope, are examined for each country. The preferred specification for each country passes the evaluation for residuals and auxiliary residuals. The test results for the selected countries are given in Table A1 in Appendix.

Primary energy supply, real GDP per capita, and manufacturing value added are found to be significant drivers for $\mathrm{CO}_{2}$ emissions of Ukraine. The estimated model may be written as:

$$
\begin{aligned}
& c_{t}=1.657 e_{t}-0.531 e_{t-1}+0.25 y_{t-1}- \\
& -0.083 m_{t}-0.086 m_{t-1}+U E T_{t} .
\end{aligned}
$$




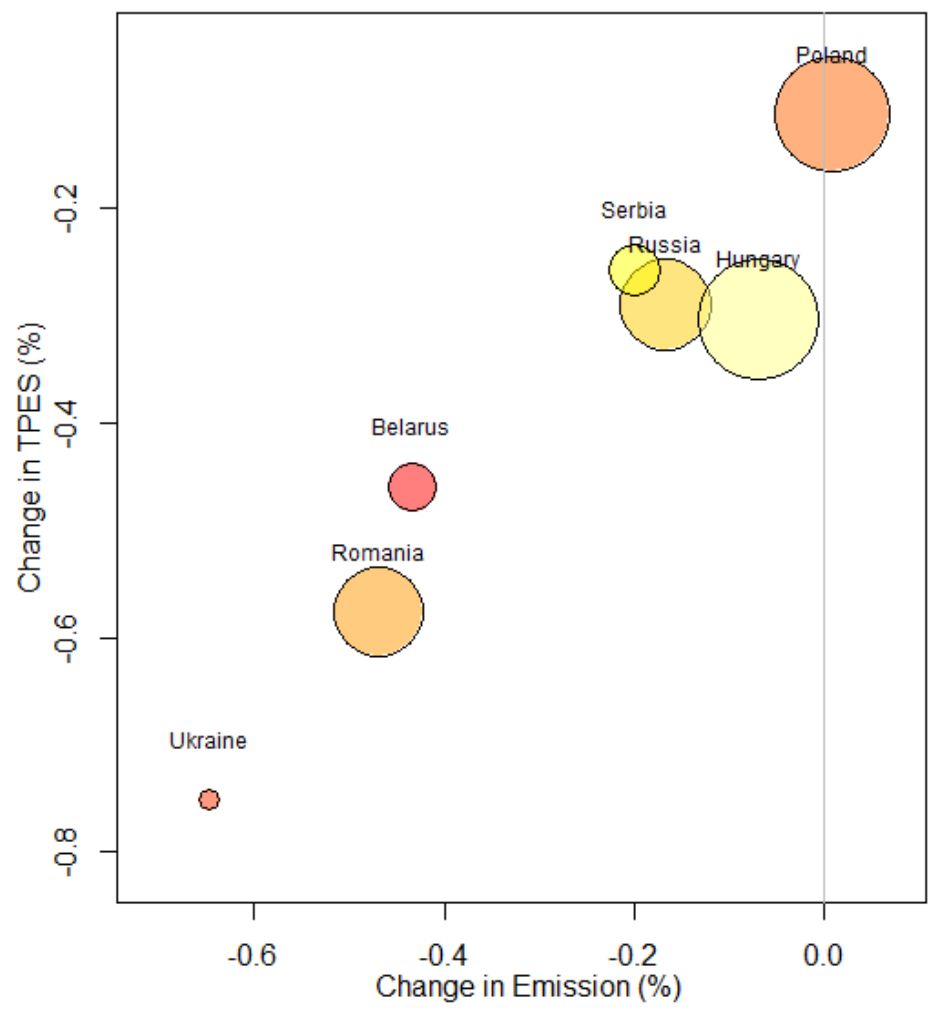

Figure 3. Change in TPES and emissions during the estimation period

As seen in Table A1, there is no autocorrelation issue, and all specifications pass the diagnostic tests. Heteroscedasticity is also not an issue as $H(5)=2.1189$ is smaller than the statistical threshold $F_{0.025,5,5}=7.146$. The period of 20102017 is used to examine the stability and reliability of the model.

As given in Table A1, primary energy supply, real GDP per capita, and manufacturing value added are detected as significant drivers of $\mathrm{CO}_{2}$ emissions for Belarus. Based on the estimated coefficients, the $\mathrm{CO}_{2}$ emissions model for Belarus is given as:

$$
\begin{aligned}
& c_{t}=0.252 e_{t}-0.196 y_{t}-0.158 y_{t-1}- \\
& -0.175 y_{t-2}+0.26 m_{t}+0.175 m_{t-1}+ \\
& +0.202 m_{t-2}+U E T_{t} .
\end{aligned}
$$

Durbin-Watson statistic with the value of 1.77 is very close to 2 , and $r_{(1)}$ is also close to 0 . This means that there is not any evidence for autocorrelation. Furthermore, $H(5)=0.6539$ is much smaller than the threshold $F_{0.025,5,5}=7.146$. Thus, it can be said that heteroscedasticity is not a problem for this model.
The established model for Poland is given in equation (8). As shown in Table A1, there is no autocorrelation and heteroscedasticity issue, since $H(5)=3.4892$ is fewer than the threshold value of $F_{0.025,5,5}=7.146$, and $\mathrm{r}_{(1)}$ is very close to 0 .

$$
\begin{aligned}
& c_{t}=0.951 e_{t}+0.179 e_{t-1}-0.052 y_{t}- \\
& -0.124 y_{t-1}+0.113 y_{t-2}+0.119 m_{t-1}- \\
& -0.12 m_{t-2}+U E T_{t} .
\end{aligned}
$$

The equation for Romania is shown further. The test statistics and residual diagnostics for Romania assert a good fit to the data and the assumptions of the model (see Table A1).

$$
\begin{aligned}
& c_{t}=1.115 e_{t}-0.137 y_{t}- \\
& -0.073 y_{t-2}+0.139 m_{t}+U E T_{t}
\end{aligned}
$$

Heteroscedasticity is not a difficulty for this model $\left(H(6)=1.5431<F_{0.025,6,6}=5.82\right)$.

For the case of Russia, the model is established as:

$c_{t}=0.763 e_{t}+0.072 y_{t-1}-0.034 m_{t-1}+U E T_{t}$. 
All of the variables are found to be significant for Russia. Different from the models mentioned above, there is an autocorrelation problem since $r(1)=-0.4422$, and Durbin-Watson test statistics with the value of 2.49 is a bit away from 2.0. However, heteroscedasticity does not cause a problem $\left(H(2)=26.991 .5431<F_{0.025,2,2}=39.0\right)$.

When the estimation results for Serbia is tackled, it can be seen that all parameters are found significant. The established model for Serbia is presented in equation (11).

$$
\begin{aligned}
& c_{t}=1.024 e_{t}+0.457 y_{t}+ \\
& +0.199 y_{t-2}-0.496 m_{t}- \\
& -0.194 m_{t-2}+U E T_{t} .
\end{aligned}
$$

Similar to the Russia case, $r_{(1)}$ and Durbin-Watson test statistics with the values of -0.26 and 2.46 , respectively, are a bit higher. This may be an indicator of an autocorrelation problem. Nonetheless, the model succeeds in all diagnostic and residual tests. Since heteroscedasticity is found $H(4)=0.4771<F_{0.025,2,2}=9.604$, there is no heteroscedasticity issue for this model.

Lastly, the established model for Hungary is given as:

$$
\begin{aligned}
& 1.111 e_{t}-0.408 y_{t-2}+0.11 m_{t}+ \\
& +0.266 m_{t-2}+U E T_{t} .
\end{aligned}
$$

Considering $H(5)=0.8353$ is less than the threshold value of $F_{0.025,5,5}=7.146$, there is no heteroscedasticity problem. Besides, autocorrelation is not a problem as $r_{(1)}$ and DW are close to 0 and 2 , respectively.

As mentioned in the previous section, UET is a stochastic trend component that adds exogenous factors such as developments in technology, changes in human behaviors, and legislation into the model. UETs for each country are shown in Figure A1 in Appendix. For Ukraine, it may be said that UET is almost linearly downward. The developments in technology, changes in human behaviors and legislation have a positive effect on reducing $\mathrm{CO}_{2}$ emissions. Similar to Ukraine, Belarus' UET shows a downward trend until 2000 and stays nearly constant until 2015. However, it starts to increase after this period. This increase in UET may indicate the changes in regulation and legislation.

For Poland, it is very obvious that there is a continuous decrease in UET after 2007. Poland became a member of the European Union (EU) in 2004 (European Union, n.d.). After becoming an EU member, Poland has to obey some environmental restrictions. The impacts of these legislations and restrictions on $\mathrm{CO}_{2}$ emissions may arise after 2007.

Hungary, Serbia, and Russia show a similar shift during the estimation period. As seen from Figure Al, the UET is deterministic rather than stochastic. However, because of the interventions, UETs of Serbia and Russia are non-linear. The estimated UETs for these three countries are decreasing permanently. Unlike other countries, Romania shows an upward trend for UET throughout the estimation period. There is a level shift in 1993, which probably reflects taking a step towards the liberalization of the market. Changes in regulations and legislations during this period may cause some reduction in $\mathrm{CO}_{2}$ emissions. Following this level shift, UET continues its increasing trend during the estimation period.

\subsection{Forecast assumptions and results}

Following the estimation of $\mathrm{CO}_{2}$ emission equations of each country, forecasting the future $\mathrm{CO}_{2}$ emissions of these countries are investigated in this section. To forecast $\mathrm{CO}_{2}$ emissions, some assumptions should be made. Total primary energy supply, GDP per capita, and manufacturing added value are extrapolated by the trend of the last 10 in-sample observations. Hereunder, the results of annual $\mathrm{CO}_{2}$ emissions forecasts (black lines) for the 2018-2027 period are shown in Figure A2 in Appendix.

Given the above assumptions, the $\mathrm{CO}_{2}$ emissions of Belarus, Ukraine, Romania, Russia, Serbia, and Hungary will descend, by 2027, to $53.15 \mathrm{Mt}, 103.18$ Mt, 36.06 Mt, 1528.16 Mt, 35.98 Mt, and 36.06 Mt, respectively. Unlike these countries, Poland has upward $\mathrm{CO}_{2}$ emissions during the forecasting period, and forecasted that $\mathrm{CO} 2$ emissions will reach 312.16 Mt in 2027. The main reason for this differ- 
ence between Poland and other countries arises due to the very high share of fossil-based supply (i.e., coal and oil) in Poland. In Poland, the total share of coal and oil in total supply is more than $75 \%$, while the average of the total share of coal and oil in total supply for the rest of Eastern European countries is approximately $45 \%$ (IEA, 2019). Thus, this situation may cause an increase in $\mathrm{CO} 2$ emissions in the future in Poland. Furthermore, Poland is the second largest coal producer country in Europe. This reserves lead much higher consumption of coal for electricity generation with a $78.3 \%$ share (Eurocoal, 2019).

When the future status of UETs is examined, it can be asserted that Ukraine, Romania, Serbia, and Hungary show a downward UET, whereas, UETs of Poland and Russia practically do not change during this period, as seen from Figure A2. Among the East European countries, the only one that has an upward UET is Belarus. This shows that the government of Belarus should change some regulations or raise awareness about GHGs in the future.

\section{DISCUSSION}

In light of the general equations of each country's $\mathrm{CO}_{2}$ emissions, long-term total primary energy supply elasticity is found quite high. This means that $\mathrm{CO}_{2}$ emissions are very sensitive to TPES as expected due to the widespread consumption of primary energy sources such as coal and oil. The long-term GDP per capita and long-term manufacturing value added of East European countries are shown in the $x$-axis and $y$-axis of Figure 4, respectively, whereas the size of the circles indicates the long-term TPES. Apart from other countries, long-term TPESs of Belarus and Russia are below 1 . The share of natural gas in TPES is much higher than other fuel types in Belarus and Russia. Compared to coal and oil, the combustion of natural gas is much more environment-friendly fuel in terms of $\mathrm{CO}_{2}$ emissions. Therefore, long-term TPESs of these two countries are relatively low than the rest of the East European countries.

Parallel to literature, energy consumption is detected as the most significant factor affecting the level of $\mathrm{CO}_{2}$ emissions. The strong connection be- tween TPES and $\mathrm{CO}_{2}$ emissions impels the governments to put some regulations and implementations into practice to encourage the private sector to invest in renewable energy sources.

Furthermore, it is a well-known fact that the energy demand of the world is continuously increasing. Governments should implement target-driven carbon taxation systems, subsidization programs, and trading strategies to go towards clean and more efficient energy sources instead of building new fossil fuel-based power plants. They may meet the growing energy demand with the inner energy sources like biogas, hydro, wind, and solar while avoiding the financial and monetary burden of shifting toward green energy with the help of the proper environmental laws and policies.

Considering GDP per capita as the economic variable, the impacts of the economic status of East European countries show different features in the long term, as seen from Figure 4. For Poland, Romania, Hungary, and Belarus, the long-term impact of economic growth on $\mathrm{CO}_{2}$ emissions is negative, while it is positive for Russia, Ukraine, and Serbia. Higher-income levels of Poland, Romania, and Hungary as EU members lead to a decreasing effect on $\mathrm{CO}_{2}$ emissions in the long term. The higher-income level may ease shifting towards green energy policies. Conversely, increases in GDP per capita have a boosting effect on $\mathrm{CO}_{2}$ emissions for Russia, Ukraine, and Serbia in the long run. This result is found very close to the findings of the study by Grytten and Koilo (2019). According to this study, $\mathrm{CO}_{2}$ emissions begin to decline after GDP per capita reaches USD 9775.56 for East European countries. As seen from Figure 3, Poland, Romania, and Hungary are the countries with the highest GDP per capita. The change in $\mathrm{CO}_{2}$ emissions in Serbia and Belarus, the most responsive countries, is found to be with values of 0.66 and -0.53 , respectively, with respect to economic development change. Besides, Poland and Russia are the least elastic countries in terms of economic development and $\mathrm{CO}_{2}$ emissions.

The impact of manufacturing on $\mathrm{CO}_{2}$ emissions is found significant for all East European countries. However, contrary to expectations, it has a mitigating impact on $\mathrm{CO}_{2}$ emissions in Ukraine and 


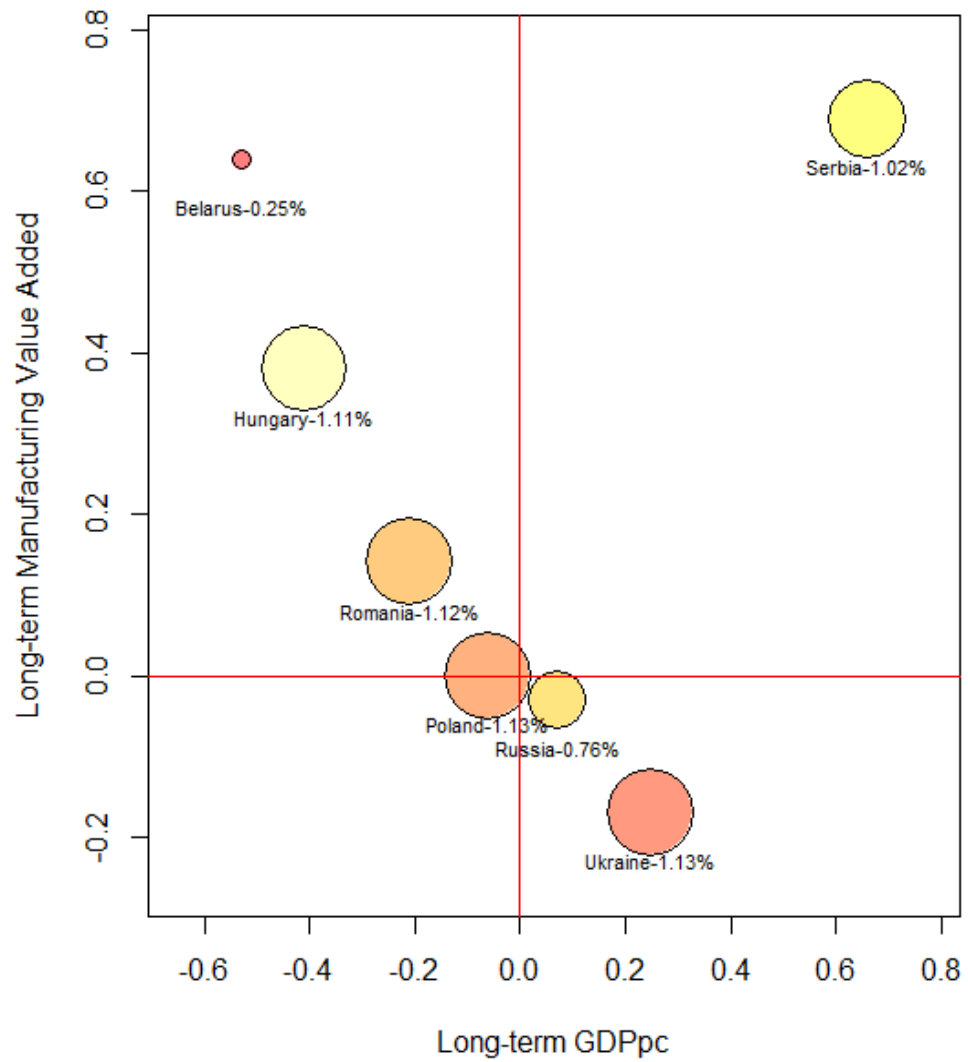

Figure 4. Long-term GDP per capita, manufacturing value added and TPES

Russia. The main reason for this situation is that the emission laws in force in Russia since 2012 compel the manufacturing sector to be more environmentally-friendly (Aris, 2019). The highest long-term manufacturing value added elastici- ty of $\mathrm{CO}_{2}$ emissions are calculated for Serbia and Belarus. This indicates that the structure of industries of these countries has higher carbon intensity or lower efficiency than that of other countries (OECD, 2014).

\section{CONCLUSION}

This paper aims to estimate $\mathrm{CO}_{2}$ emissions of East European countries depending on total primary energy supply, GDP per capita, manufacturing value added, and Underlying Emission Trend as an exogenous factor. With the annual data of the 1990-2017 period, the estimated models calculate the long-term income, total primary energy supply, and manufacturing value added elasticities of each country using the STSM approach. The paper's results indicate that the most forceful factor in $\mathrm{CO}_{2}$ emissions is the total primary energy supply.

Long-term GDP per capita elasticities of Russia, Serbia, and Ukraine are found positive. Besides, Serbia and Belarus are detected to be the most sensitive countries with respect to economic growth. The highest long-term manufacturing value added elasticity of $\mathrm{CO}_{2}$ emissions is obtained for Serbia and Belarus.

The model forecasts that $\mathrm{CO}_{2}$ emissions of Belarus, Ukraine, Romania, Russia, Serbia, and Hungary will decrease, by 2027, to $53.2 \mathrm{Mt}, 103.2 \mathrm{Mt}, 36.1 \mathrm{Mt}, 1528.2 \mathrm{Mt}, 36 \mathrm{Mt}$, and $36.1 \mathrm{Mt}$, respectively. Distinct from other countries, $\mathrm{CO}_{2}$ emissions of Poland will extend to $312.2 \mathrm{Mt}$ in 2027.

Moreover, UETs of Ukraine, Romania, Serbia, and Hungary show a downward trend, while UETs of Poland and Russia do not vary during the forecasting period. However, Belarus has an upward UET. 
The upward-sloping UET indicates that the efficiency of manufacturing and energy generation sectors has decreased throughout this period or has improved but was outweighed by other exogenic determinants such as politics.

\section{RECOMMENDATIONS}

This analysis could be extended to involve the cultural changes after liberation and considering the social impacts of industrialization. Though technology impacts on $\mathrm{CO}_{2}$ emissions are widely studied, possibilities of ecological use of technology are rarely studied.

Technological changes in Industry 4.0 in East European countries are still to be studied with the impact on $\mathrm{CO}_{2}$ emissions. Despite the increase in industrial awareness, the increase in robotics causes more energy use. Hence, this subject is to be studied together with the changes in energy resources. As an example, renewable energy and storage replacing the old nuclear bases will cause changes in responding to the demand for industrial energy.

It is also recommended to use other stochastic methods for prescriptive analytics to foresee the GDP of the same countries with reaction to global changes like 2020.

\section{AUTHOR CONTRIBUTIONS}

Formal analysis: Denizhan Guven.

Methodology: Denizhan Guven.

Supervision: M. Ozgur Kayalica.

Visualization: Denizhan Guven.

Writing - review \& editing: M. Ozgur Kayalica, Gulgun Kayakutlu.

Writing- original draft: Denizhan Guven, M. Ozgur Kayalica.

\section{REFERENCES}

1. Antanasijević, D. Z., Ristić, M. Đ., Perić-Grujić, A. A., \& Pocajt, V. V. (2014). Forecasting GHG emissions using an optimized artificial neural network model based on correlation and principal component analysis. International Journal of Greenhouse Gas Control, 20, 244-253. https://doi. org/10.1016/j.ijggc.2013.11.011

2. Aris, B. (2019, September 30). The Cost of Carbon in Russia. The Moscow Times. Retrieved from https://www.themoscowtimes. com/2019/09/30/the-cost-ofcarbon-in-russia-a67496

3. Atalla, T. N., \& Hunt, L. C. (2016). Modelling residential electricity demand in the GCC countries. Energy Economics, 59, 149-158. https://doi.org/10.1016/j.eneco.2016.07.027
4. Dilaver, Z., \& Hunt, L. C. (2011). Industrial electricity demand for Turkey: a structural time series analysis. Energy Economics, 33(3), 426-436. https://doi.org/10.1016/j. eneco.2010.10.001

5. Eurocoal. (2019). The country profiles: Poland. Retrieved June, 04, 2020 from https://euracoal.eu/ info/country-profiles/poland/

6. European Union. (n.d.). $E U$ member countries in brief. Retrieved April, 24, 2019 from https://europa.eu/europeanunion/about-eu/countries/member-countries_en

7. Grytten, O. H., \& Koilo, V. (2019). Evidence of the Environmental Kuznets Curve in Emerging Eastern European Economies (NHH Dept. of Economics Discussion Paper SAM 11/2019). Retrieved from https://www.researchgate.net/ publication/333670107_Evidence_ of_the_Environmental_Kuznets_ Curve_in_Emerging_Eastern_European_Economies

8. Harvey, A. C. (1997). Trends, cycles and autoregressions. The Economic Journal, 107(440), 192201. https://doi.org/10.1111/14680297.00152

9. Harvey, A. C., \& Koopman, S. J. (1992). Diagnostic checking of unobserved-components time series models. Journal of Business \& Economic Statistics, 10(4), 377389. Retrieved from https://www. jstor.org/stable/1391813

10. Harvey, A. C., \& Shephard, N. (1993). 10 Structural time series models. Handbook of Statistics, 11, 261-302. https://doi.org/10.1016/ S0169-7161(05)80045-8 
11. Harvey, A. C., Henry, S. G. B., Peters, S., \& Wren-Lewis, S. (1986). Stochastic trends in dynamic regression models: An application to the employmentoutput equation. The Economic Journal, 96(384), 975-985. https:// doi.org/10.2307/2233168

12. Hendry, D., \& Juselius, K. (2000). Explaining Cointegration Analysis: Part I. The Energy Journal, 21(1), 1-42. Retrieved from https://econpapers.repec.org/ article/aenjournl/2000v21-01-a01. htm

13. Hunt, L. C., Judge, G., \& Ninomiya, Y. (2000). Modelling technical progress: an application of the stochastic trend model to UK energy demand (99 p.). Guildford: Surrey Energy Economics Centre. Retrieved from https:// www.researchgate.net/publication/24133924_Modelling_Underlying_Energy_Demand_Trends

14. IEA. (2019). CO2 Emissions from Fuel Combustion. https://doi. org/10.1787/2a701673-en

15. Jebli, M. B., Farhani, S., \& Guesmi, K. (2020). Renewable energy, CO2 emissions and value added: Empirical evidence from countries with different income levels. Structural Change and Economic Dynamics, 53, 402-410. https://doi. org/10.1016/j.strueco.2019.12.009

16. Köne, A. Ç., \& Büke, T. (2010). Forecasting of $\mathrm{CO} 2$ emissions from fuel combustion using trend analysis. Renewable and Sustainable Energy Reviews, 14(9), 2906-2915. https://doi. org/10.1016/j.rser.2010.06.006

17. Koopman, S. J., Harvey, A. C., Doornik, J. A., \& Shephard, N (2007). STAMP 8.0: Structural time series analyser, modeller and predictor. London: Timberlake Consultants.

18. Le Quéré, C., Andrew, R. M., Friedlingstein, P., Sitch, S., Hauck, J., Pongratz, J., ... \& Arneth, A. (2018). Global carbon budget 2018. Earth System Science Data, 10(4), 2141-2194. Retrieved from https://www.earth-syst-sci-data. net/10/2141/2018/essd-10-21412018.pdf
19. Maddala, G. S., \& Kim, I. M. (1998). Unit roots, cointegration, and structural change. Cambridge University Press. https://doi. org/10.1017/CBO9780511751974

20. OECD. (2014). Perspectives on Global Development 2014: Boosting Productivity to Meet the Middle-Income Challenge. OECD Publishing. https://doi. org/10.1787/persp_glob_dev2014-en

21. Olivier, J. G., Schure, K. M., \& Peters, J. A. H. W. (2018). Trends in global $\mathrm{CO} 2$ and total greenhouse gas emissions. PBL Netherlands Environmental Assessment Agency. Retrieved from https:// www.pbl.nl/en/publications/ trends-in-global-co2-and-totalgreenhouse-gas-emissions

22. Pérez-Suárez, R., \& LópezMenéndez, A. J. (2015). Growing green? Forecasting $\mathrm{CO} 2$ emissions with environmental Kuznets curves and logistic growth models. Environmental Science \& Policy, 54, 428-437. https://doi.org/10.1016/j. envsci.2015.07.015

23. Ritchie, H., \& Roser, M. (2019). $\mathrm{CO}_{2}$ and Greenhouse Gas Emissions. Retrieved from https:// ourworldindata.org/co2-and-other-greenhouse-gas-emissions

24. Scripps Institution of Oceanography. (2020). Scripps $\mathrm{CO}_{2}$ Program: Carbon dioxide concentration at Manua Loa Observatory. Retrieved from https://scripps.ucsd.edu/programs/keelingcurve/

25. Song, Y., \& Zhang, M. (2019). Study on the gravity movement and decoupling state of global energy-related $\mathrm{CO} 2$ emissions. Journal of Environmental Management, 245, 302-310. https://doi.org/10.1016/j.jenvman.2019.05.094

26. Stocker, T. F., Qin, D., Plattner, G. K., Tignor, M., Allen, S. K., Boschung, J., ... \& Midgley, P. M. (2013). Climate Change 2013: The Physical Science Basis. Contribution of Working Group I to the Fifth Assessment Report of the Intergovernmental Panel on Climate Change. Retrieved from https://www.ipcc.ch/site/
assets/uploads/2017/09/WG1AR5_ Frontmatter_FINAL.pdf

27. UNFCCC. (2015). Intended Nationally Determined Contributions (INDCs). Retrieved from https://unfccc.int/files/adaptation/application/pdf/all__parties_indc.pdf

28. Wei, Y., Li, Yan., Wu, M., \& Li, Yingbo. (2019). The decomposition of total-factor CO2 emission efficiency of 97 contracting countries in Paris Agreement. Energy Economics, 78, 365-378. https://doi.org/10.1016/j. eneco.2018.11.028

29. World Bank. (2019a). World Development Indicators: GDP. Retrieved from https://data. worldbank.org/indicator/NY.GDP. MKTP.CD

30. World Bank. (2019b). World Development Indicators: Manufacturing, Value Added. Retrieved from https://data. worldbank.org/indicator/NV.IND. MANF.CD 
Table A1. Estimated results for each country

\begin{tabular}{|c|c|c|c|c|c|c|c|}
\hline Estimated coefficients & Ukraine & Belarus & Poland & Romania & Russia & Serbia & Hungary \\
\hline$\alpha_{0} \ldots$ & - & - & - & - & - & - & - \\
\hline$\alpha_{1}$ & - & -1 & - & - & - & - & - \\
\hline$\vartheta_{0}$ & $1.6574 *$ & $0.2516^{*}$ & $0.9512^{*}$ & $1.1153^{*}$ & $0.7632 *$ & $1.024 *$ & $1.1109 *$ \\
\hline$\theta_{1}$ & $-0.5310 * *$ & $-\ldots$ & $0.1790^{*}$ & $-\ldots$ & $-\ldots$ & $-\ldots$ & $-\ldots$ \\
\hline$Y_{0}$ & - & $-0.1956 * *$ & $-0.0517^{*}$ & $-0.1373^{* *}$ & - & $0.4565^{*}$ & - \\
\hline$v_{1}$ & $0.2497 *$ & $-0.1581^{*}$ & $-0.1238^{*}$ & $-\ldots$ & $0.0718^{*}$ & $\ldots$ & - \\
\hline$\gamma_{2}$ & - & $-0.1747 *$ & $0.1134 *$ & $-0.0733^{* *}$ & - & $0.1993^{*}$ & $-0.4076^{*}$ \\
\hline$\theta_{0}$ & $-0.0826^{* *}$ & $0.2601^{*}$ & $-\ldots$ & $0.1392^{* *}$ & $-0.0343^{*}$ & $-0.4963^{*}$ & $0.1111^{*}$ \\
\hline$\theta_{1}$ & $-0.0855^{* * *}$ & $0.1751^{*}$ & $0.1189^{*}$ & - & - & - & - \\
\hline$\theta_{2}$ & - & $0.2023^{*}$ & $-0.1205^{*}$ & - & - & $-0.1942^{*}$ & $0.2655^{* * *}$ \\
\hline \multicolumn{8}{|c|}{ LR elasticity } \\
\hline$\Gamma$ & 1.1264 & 0.2516 & 1.1302 & 1.1153 & 0.7632 & 1.024 & 1.1109 \\
\hline$\Delta$ & 0.2497 & -0.5284 & -0.0621 & -0.2106 & 0.0718 & 0.6558 & -0.4076 \\
\hline$\Theta$ & -0.1681 & 0.6375 & 0.0 & 0.1392 & -0.0343 & 0.6905 & 0.377 \\
\hline \multicolumn{8}{|c|}{ Hyper-parameters } \\
\hline Irregular & 0.0222 & 0.00008 & 0.0 & 0.0002 & 0.00002 & 0.0003 & 0.0004 \\
\hline Level & 0.0 & 0.00005 & 0.00004 & 0.0 & 0.0 & 0.0 & 0.0 \\
\hline Slope & 0.0037 & 0.00004 & 0.0 & 0.0 & 0.0 & 0.0 & 0.0 \\
\hline Interventions & $\begin{array}{c}-0.1739 \\
\text { Outlier(2010)* }\end{array}$ & $\begin{array}{c}0.0711 \\
\text { Outlier (2010)* }\end{array}$ & $\begin{array}{c}-0.0270 \\
\text { Outlier }(1993)^{*} \\
-1.1894 \\
\text { Outlier }(1996)^{*}\end{array}$ & $\begin{array}{c}-0.0696 \\
\text { Level }(1993)^{*}\end{array}$ & $\begin{array}{c}-0.0489 \\
\text { Outlier (2009)* }\end{array}$ & $\begin{array}{c}-0.095 \\
\text { Outlier }(2003)^{*} \\
-0.0717 \\
\text { Outlier }(2010)^{*}\end{array}$ & - \\
\hline \multicolumn{8}{|c|}{ Goodness of fit } \\
\hline p.e.v. & 0.00088 & 0.00021 & 0.00003 & 0.0003 & 0.00002 & 0.0002 & 0.0003 \\
\hline AIC & -6.3912 & -7.6918 & -9.4906 & -7.5548 & -10.363 & -7.7843 & -7.6035 \\
\hline$R^{2}$ & 0.99 & 0.99 & 0.99 & 0.99 & 0.99 & 0.99 & 0.98 \\
\hline$R_{d}^{2}$ & 0.90 & 0.96 & 0.98 & 0.95 & 0.99 & 0.99 & 0.88 \\
\hline \multicolumn{8}{|c|}{ Residual diagnostics } \\
\hline Std. error (\%) & 2.9 & 1.4 & 0.5 & 1.7 & 0.4 & 1.4 & 1.8 \\
\hline Normality & 0.3552 & 0.8026 & 4.7184 & 0.4732 & 0.2534 & 0.3604 & 0.0404 \\
\hline$H(h)$ & $H_{(5)}=2.1189$ & $H_{(5)}=0.6539$ & $H_{(5)}=3.4892$ & $H_{(6)}=1.5431$ & $H_{(2)}=26.991$ & $H_{(4)}=0.4771$ & $H_{(5)}=0.8353$ \\
\hline$r_{(1) \ldots \ldots}$ & -0.4731 & -0.1393 & -0.0179 & -0.0603 & -0.422 & -0.245 & 0.0209 \\
\hline$r_{(q) \ldots}$ & $r_{(5)}=0.073$ & $r_{(5)}=-0.268$ & $r_{(5)}=-0.054$ & $r_{(5)}=-0.121$ & $r_{(5)}=-0.189$ & $r_{(5)}=0.132$ & $r_{(5)}=-0.045$ \\
\hline DW & 2.6292 & 1.7771 & 1.8676 & 2.0851 & 2.4883 & 2.4567 & 1.7306 \\
\hline$Q(p, d)$ & $Q_{1531}=9.499$ & $\mathrm{Q}_{(5,3)}=3.174$ & $\mathrm{Q}_{(5,3)}=0.935$ & $\mathrm{Q}_{153 \mathrm{l}}=6.1748$ & $Q_{(5,3)}=7.094$ & $\mathrm{Q}_{(5,3)}=6.618$ & $\mathrm{Q}_{1532}=5.856$ \\
\hline
\end{tabular}

Notes: $* * *, * *$ denote statistical significance at $1 \%, 5 \%$, and $10 \%$, respectively. p.e.v. is the prediction error variance, and AIC is the Akaike information criterion. $\mathrm{R}^{2}$ is the coefficient of determination, and $R_{d}^{2}$ is the coefficient of determination based on differences, a measure that benchmarks the estimated model against the random walk with drift. Mathematically, $R_{d}^{2}=1-S S E / \sum^{T}\left(\Delta y_{t}-\Delta y\right)^{2}$, where SSE is short for Sum of Squared Errors and $\Delta y$ is the mean of the first differences (Harvey, 1989). DW is the Durbin-Watson statistic. $\mathrm{r}_{(1)}$ is the estimated residual autocorrelations at lag 1 distributed approximately as $\mathrm{N}(0,1 / \mathrm{T})$. Normality is the Bowman-Shenton statistic of the third and fourth moments of the residuals that are approximately $\chi_{2}^{2} . \mathrm{H}(\mathrm{h})$ is a measure of heteroscedasticity that follows approximately $F_{h, h}$. $\mathrm{Q}(\mathrm{p}, \mathrm{d})$ is the Box-Ljung statistic depending on the first $p$ autocorrelations that follow a Chisquare distribution. 
Ukraine

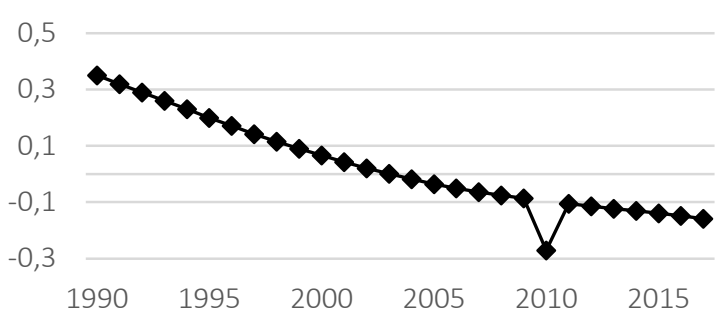

Belarus

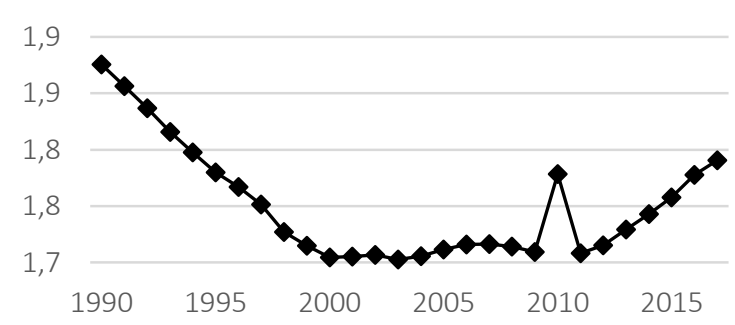

Hungary

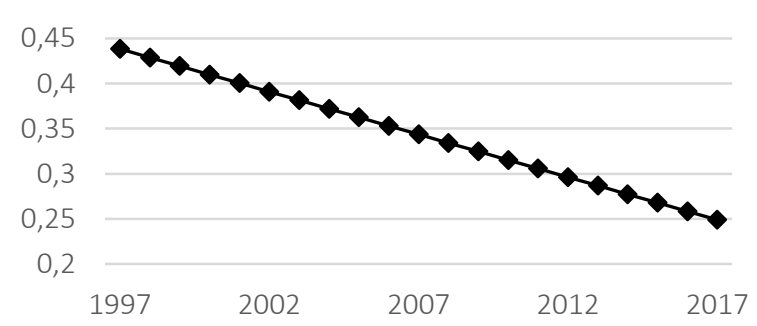

\section{Russia}

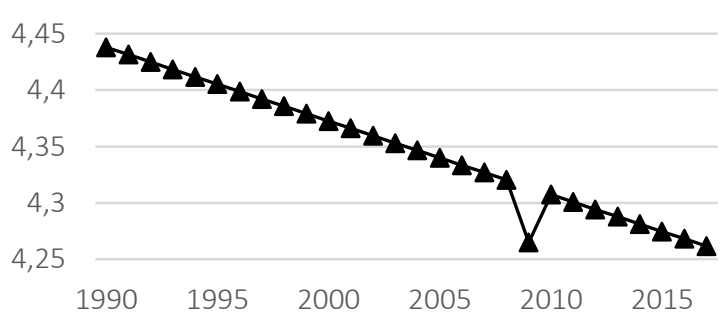

Poland

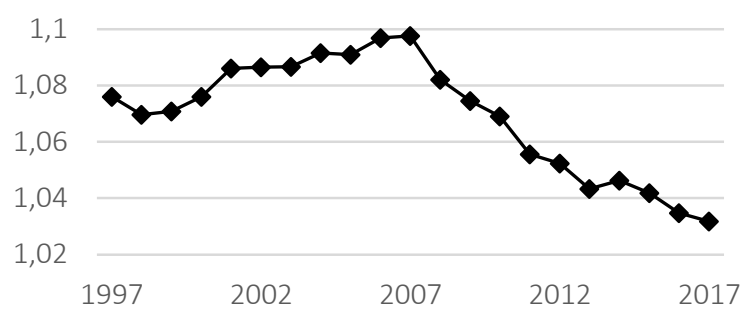

Romania

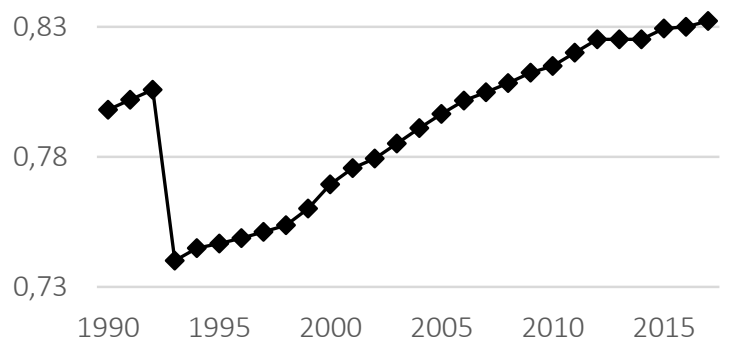

Serbia

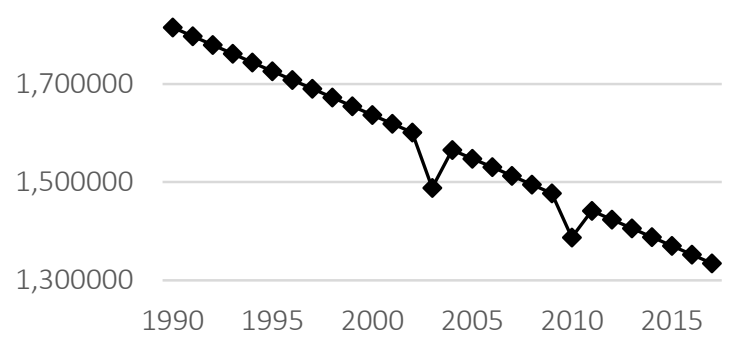

Figure A1. Underlying $\mathrm{CO}_{2}$ emissions trends 
Belarus

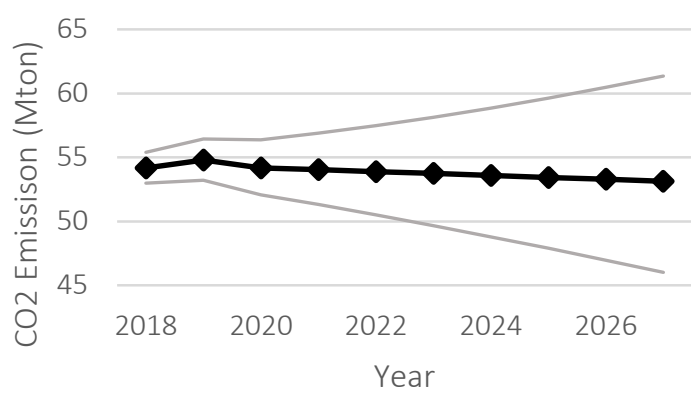

Ukraine

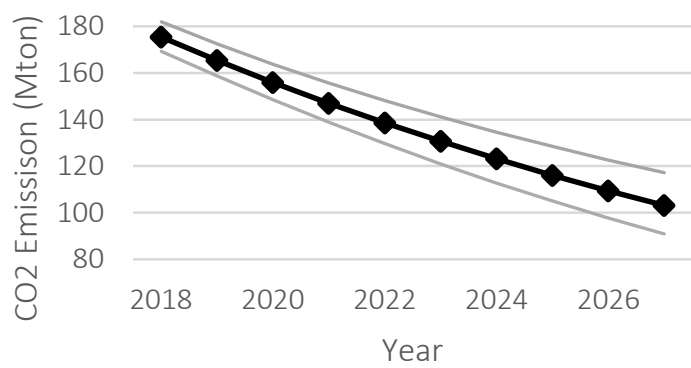

Poland

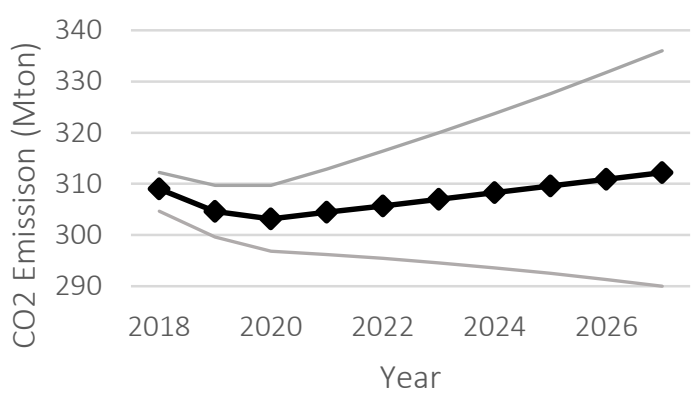

Romania

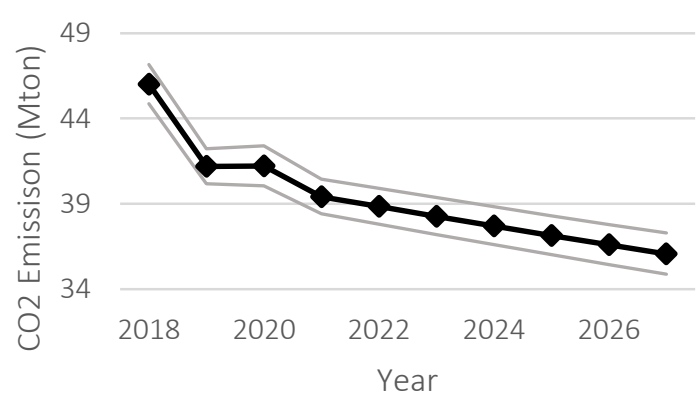

Belarus UET

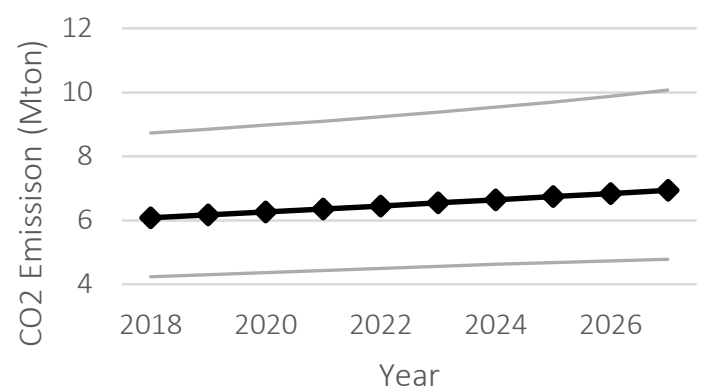

Ukraine UET

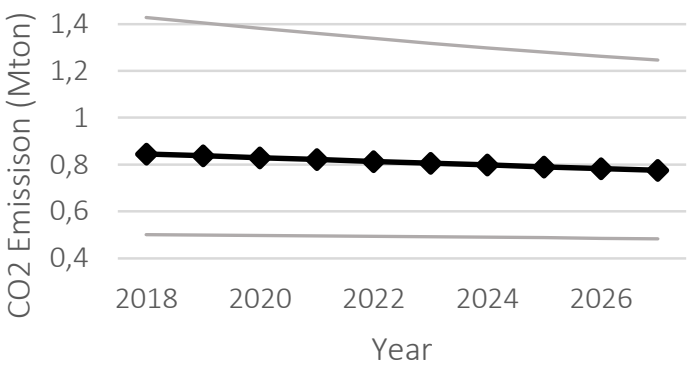

Poland UET

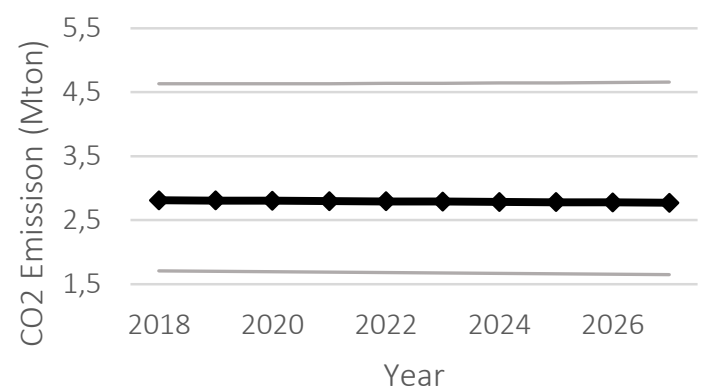

Romania UET

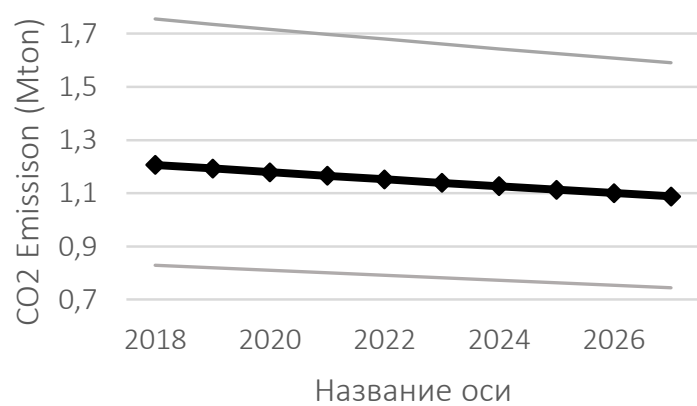

Figure A2. Forecast results and UETs for each country 
Russia

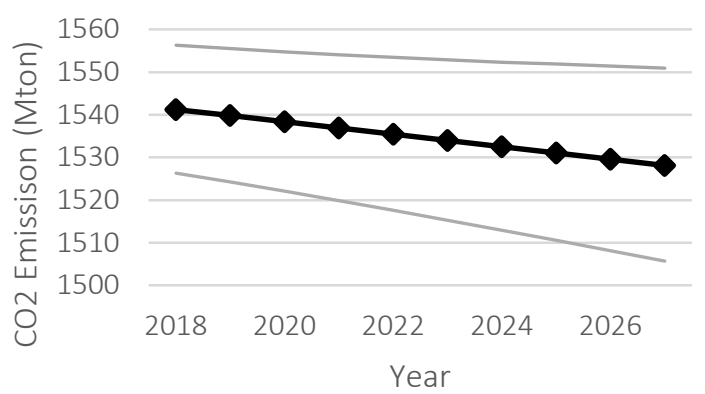

Serbia

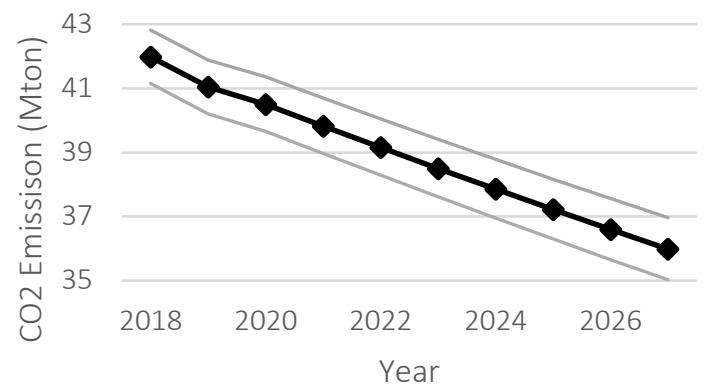

Hungary

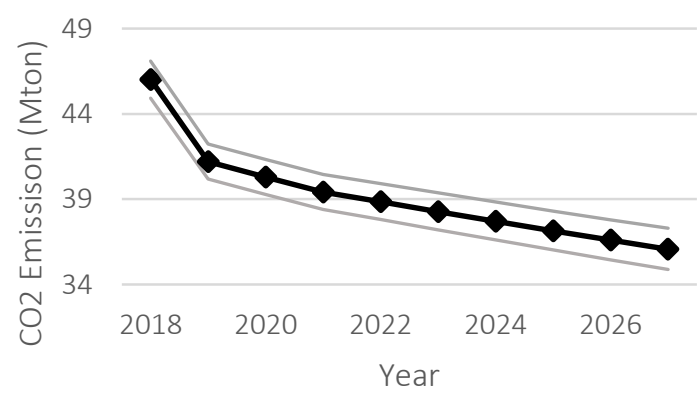

Russia UET

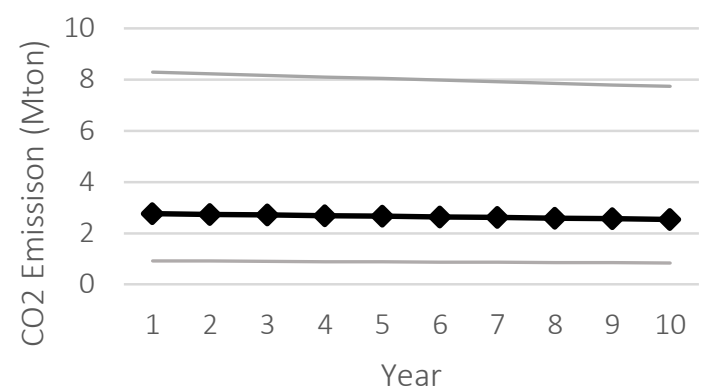

Serbia UET

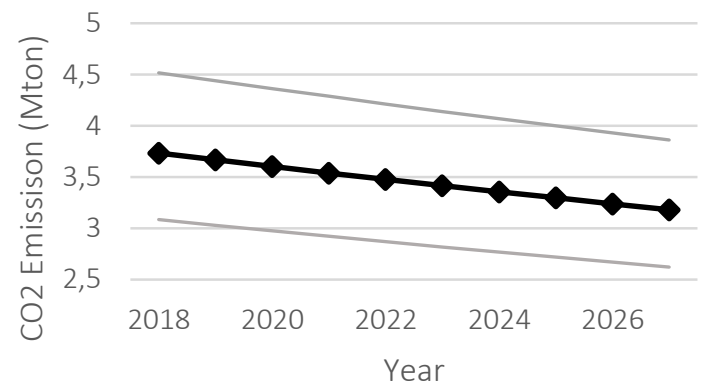

Hungary UET

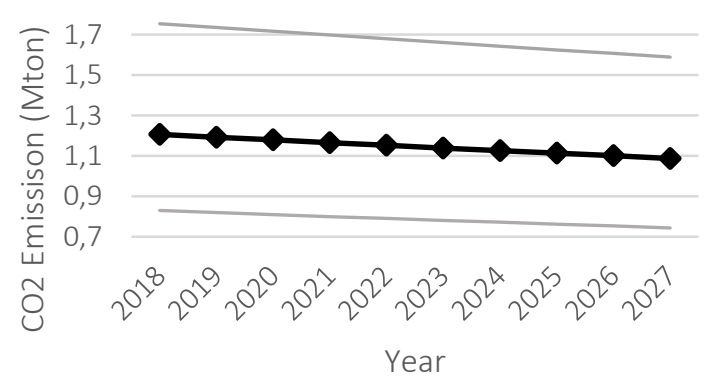

Figure A2 (cont.). Forecast results and UETs for each country 